\title{
PERCUSSION CAPACITOR-DISCHARGE WELDING OF WIRE OF COMPOSITE SUPERCONDUCTING ALLOY
}

\author{
D.M. KALEKO \\ E.O. Paton Electric Welding Institute, NASU \\ 11 Bozhenko Str., 03680, Kiev, Ukraine. E-mail: office@paton.kiev.ua
}

\begin{abstract}
Urgency of application of superconducting wires in medical and experimental equipment requires, considering limited length of wire and its high cost, development of joining methods, preserving service characteristics of a base metal. Structure of composite wire, consisting of several dozens of threads from superconducting alloy in copper matrix, allows application of only solid-phase methods of welding. Percussion capacitor-discharge welding is the most perspective for butt joining of such small diameter wires. It provides the possibility of simultaneous welding of threads and matrix, having extremely different thermal-physical characteristics. It is shown that this method allows producing of the joints of commercial composite wires of 0.85 and $1 \mathrm{~mm}$ diameter from NT-50 niobium-titanium alloy in copper matrix without significant reduction of critical current in up to $80 \mathrm{kOe}$ fields. 2 Ref., 2 Tables, 4 Figures.
\end{abstract}

$\boldsymbol{K} \boldsymbol{e} \boldsymbol{y} \boldsymbol{w} \boldsymbol{o r d} \boldsymbol{s}:$ percussion capacitor-discharge welding, composite wire, superconducting wire, niobium-titanium alloy

Production of superconducting materials based on $\mathrm{Nb}-\mathrm{Ti}$ alloy and $\mathrm{Nb}_{3} \mathrm{Sn}$ intermetallic was expanded in recent years due to works on project of the International Thermonuclear Experimental Reactor. $\mathrm{Ni}-\mathrm{Ti}$ alloy $(\mathrm{Nb}-47.5 \% \mathrm{Ti})$ due to high technological characteristics, namely strength and ductility, is the basic material for technical application of superconductors, main of which are coils of tomopgraphs for magnetic resonance therapy and nuclear magnetic resonance. The superconductors have also found application in the magnets of research power installations of Tokamak type, in the pilot models of superconducting induction energy storages, cables, magnetic separators etc.

At present time series of companies, including Supercon (USA), Western Superconducting Technologies (China), Chepetsky Mechanical Plant of TVEL Corporation (Russia) and others, mastered manufacture and propose for sale $\mathrm{Ni}-\mathrm{Ti}$ wire of 0.3 to $2.0 \mathrm{~mm}$ diameter.

A structure of wire - thread of $\mathrm{Nb}-\mathrm{Ti}$ alloy in copper matrix - is determined by the requirements of preservation of superconducting characteristics in magnetic field of up to $10 \mathrm{~T}$ value. For this, the $\mathrm{Ni}-\mathrm{Ti}$ rods are laid in the cylindrical channels of copper semi-product and such a composition is treated by pressure and drawn in a wire. Cold deformation results in appearance of high dislocation density and structural defects, which serve as centers of locking of magnetic vortexes (so called pinning), and this, after cor- responding annealing, provides for necessary current density at high magnetic field intensity [1].

One more condition for successful operation of $\mathrm{Ni}-\mathrm{Ti}$ composite superconductor is spiral twisting of the Ni-Ti threads (twisting). Such peculiarity of the structure results in change of orientation of applied field, that allows reducing time of attenuation of loop-forming screen currents by passing along one side of the conductor and returning through the copper matrix to opposite side. Step of twisting, in general, depends on conditions of wire operation and have order of several centimeters. Figure 1 shows cross-section of the superconducting $\mathrm{Ni}-\mathrm{Ti}$ wire.

Manufacture of the devices, using superconducting wires, requires joining wires between

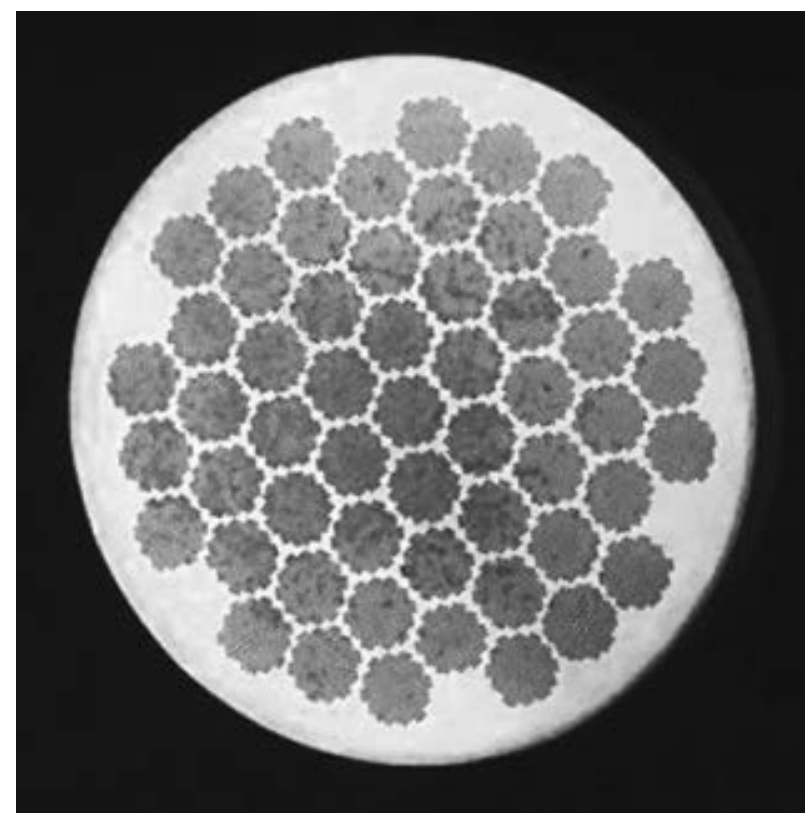

Figure 1. Cross-section of NT-50 alloy wire of $1 \mathrm{~mm}$ diameter 


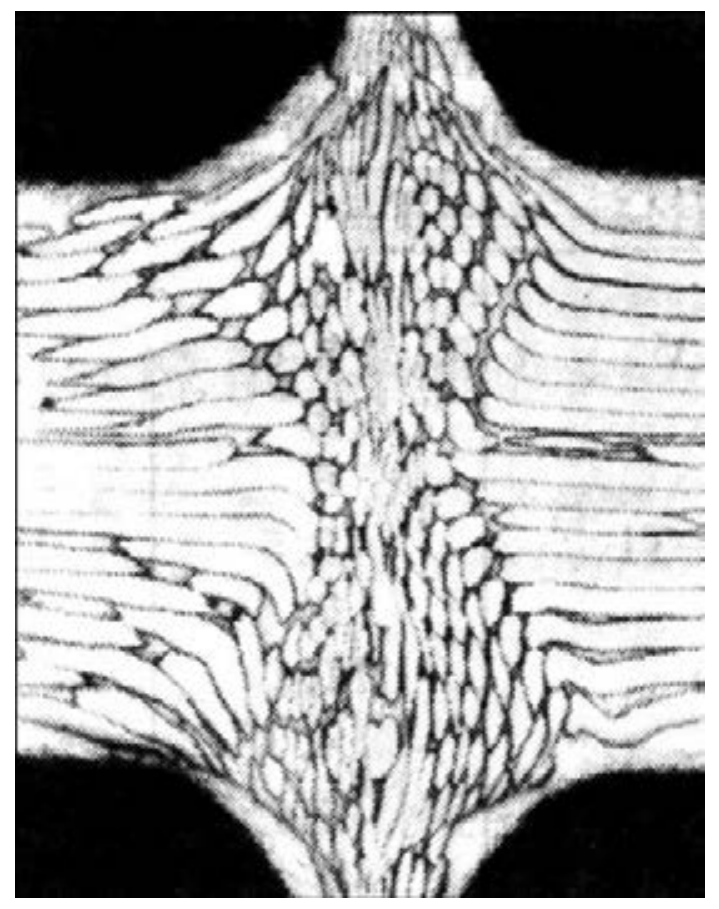

Figure 2. Macrostructure of cold-welded joint of composite superconducting wire [2]

each other, considering its high cost and length, limited by production technology. Now it is performed by parallel laying of ends of the wires being joined with subsequent brazing-on of copper matrix along the significant length, since it is necessary to provide not only joint strength, but also the possibility of conduction of current in several tens of kiloamperes through copper, keeping electrical resistance.

Experiments were carried out on joining of fragments of wire by removing (etching) the copper matrix from superconducting alloy threads with subsequent covering of the welded joint by copper [2]. It is shown in this work that the best result is received in joining of the threads without flashing, for example, at pressing by copper tube

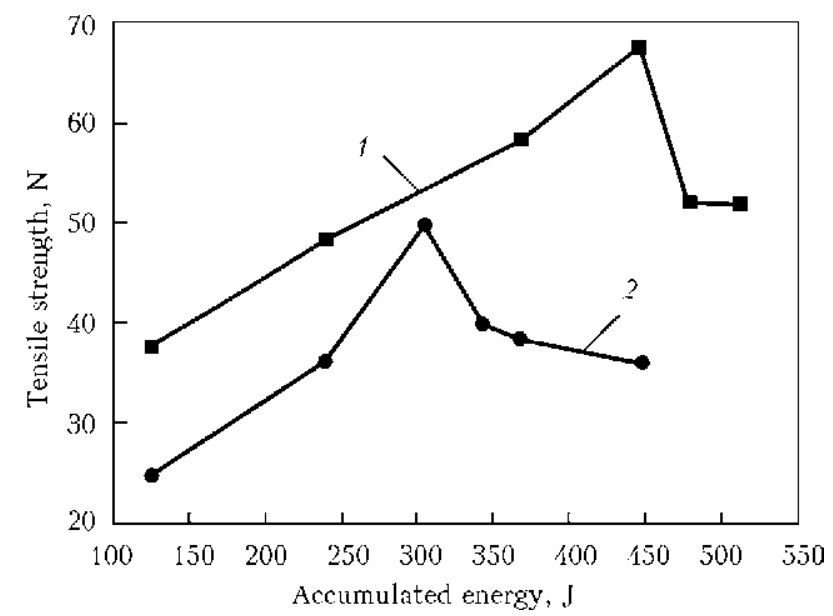

Figure 3. Dependence of joint strength of composite superconducting NT-50 wires in copper matrix, made by percussion capacitor-discharge welding, on accumulated energy (diameter of wires being joined 1 (1) and 0.85 (2) $\mathrm{mm}$ of the composition of threads, which mutually come into fragments of wire being joined. At that, the experiments with electron beam welding of threads showed significant (by 2 orders) reduction of critical current passing through the joint.

Laboriousness of described operation of mechanical joining provokes searching of the methods for butt joining of the wires in a way to provide simultaneous welding of threads of superconducting material and copper matrix. Obviously, that searching can be carried out only among the methods of solid-phase welding. Considering form of the joint, cold and percussion capacitor-discharge welding can be referred to such. Advantage of the latter lies in low level of deformation and, due to this, preservation of composite structure. Cold welding requires application of significant forces, which result in breaking of the threads of superconducting material and their distortion (Figure 2). Therefore, percussion capacitor-discharge welding is more preferable for joining of composite wire.

Joining in percussion capacitor-discharge welding takes place in upsetting of wires being joined after cleaning and heating of welded surfaces by arc burning at capacitor discharge. Compression of the wires results in removal of molten metal in flash and formation of metallic bonds of the surfaces being joined. Initial characteristics of the metal are preserved due to this, and certain increase of joint area makes it full-strength with the base metal.

The experiments were carried out using wires of composite alloy NT-50 (47.5 wt.\% Ti, the rest is $\mathrm{Ni}$ ) in the copper matrix of $1 \mathrm{~mm}$ diameter (quantity of threads $n=37$, space factor $F_{\mathrm{s}}=$ $=45.4 \%), 0.85 \mathrm{~mm}\left(n=37, F_{\mathrm{s}}=46.38 \%\right)$ and $0.5 \mathrm{~mm}\left(n=24, F_{\mathrm{s}}=32.12 \%\right)$. Welding was performed on universal machine A-1091 for arc methods of capacitor-discharge welding. Modes of welding are shown in Table 1. Satisfactory quality of joints of $0.5 \mathrm{~mm}$ diameter wire was not succeeded.

Figure 3 shows effect of mode parameters on tensile strength of the joint. The mode of welding, at which the specimens fracture along the solid

Table 1. Modes of percussion capacitor-discharge welding of composite superconducting $\mathrm{Ni}-\mathrm{Ti}$ wire (resistance of discharge loop $1.2 \mathrm{Ohm}$ )

\begin{tabular}{||c|c|c|c||}
\hline $\begin{array}{c}\text { Wire diameter, } \\
\mathrm{mm}\end{array}$ & $\begin{array}{c}\text { Capacity of } \\
\text { capacitors, } \mu \mathrm{F}\end{array}$ & $\begin{array}{c}\text { Charging } \\
\text { voltage of } \\
\text { capacitors, } \mathrm{V}\end{array}$ & $\begin{array}{c}\text { Percussion } \\
\text { force, } \mathrm{N}\end{array}$ \\
\hline 1 & 1500 & 770 & 10 \\
\hline 0.85 & 1400 & 660 & 8 \\
\hline
\end{tabular}


Table 2. Values of current in liquid helium

\begin{tabular}{||l|c|c|c||}
\hline \multirow{2}{*}{ Specimen } & \multicolumn{3}{|c|}{$\begin{array}{c}\text { Critical average current, A, in } \\
\text { magnetic field, kOe }\end{array}$} \\
\cline { 2 - 4 } & 50 & 60 & 70 \\
\hline $\begin{array}{l}\text { Initial material of 1 mm } \\
\text { diameter }\end{array}$ & - & 582 & 438 \\
\hline Welded specimen & - & 577 & 427 \\
\hline $\begin{array}{l}\text { Initial material of } 0.85 \mathrm{~mm} \\
\text { diameter }\end{array}$ & 414 & 326 & 257 \\
\hline Welded specimen & 389 & 299 & 246 \\
\hline
\end{tabular}

wire far from place of welding, was taken as the optimum one. Such a choice was verified by measurement of operating characteristics.

Microstructure of the welded joints of superconducting composite wire NT-50 of $1 \mathrm{~mm}$ diameter (Figure 4) shows performance of the joints of separate threads of superconducting alloy as well as copper matrix in the process of percussion capacitor-discharge welding. Inhomogeneity of NT-50 threads out of the joint, which can be seen in microsection photo, is explained by non-parallelism of «twisted» thread and microsection plain.

Since it is impossible to adjust accurately the threads of stranded fragments of composite wire being joined during welding, welded joints of superconductor with copper matrix appear in the butt. Based on data of metallographic analysis, possibility of joining of separate threads between each other makes around $80 \%$.

Measurements of electric resistance in $5 \mathrm{~m}$ length specimens of $1 \mathrm{~mm}$ diameter NT-50 wire having 20 butts, carried in the I.V. Kurchatov Institute of Atomic Energy, at $4.2 \mathrm{~K}$ temperature in $80 \mathrm{kOe}$ intensity magnetic field, showed value around $0.1 \mu \mathrm{Ohm}$. The critical currents in liquid helium, measured in the All-Russian Research Institute of Cable Industry, are given in Table 2.

The Table shows that the welded joint critical current, which is one of the main characteristics

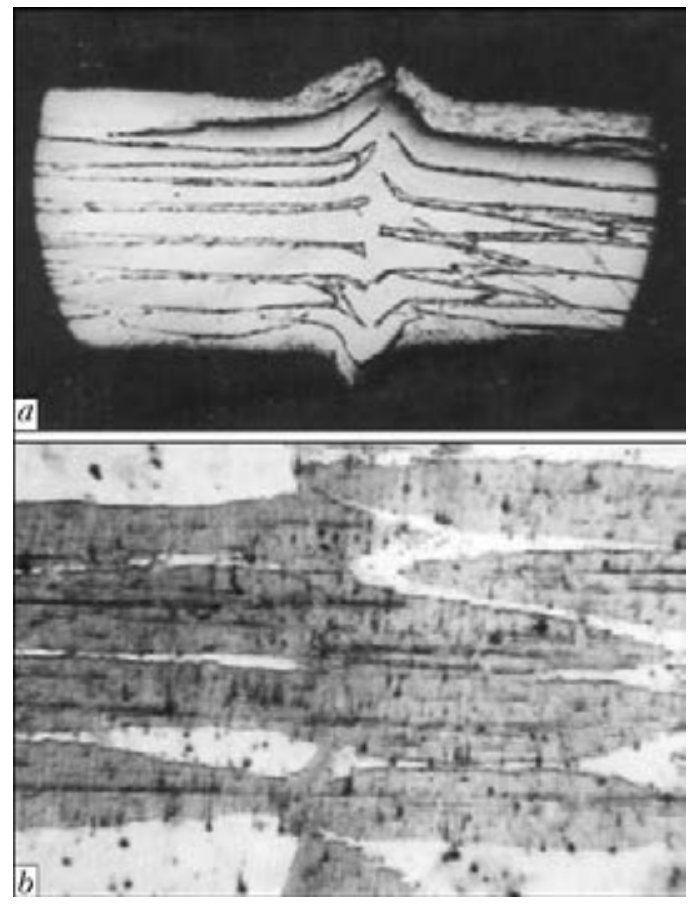

Figure 4. Microstructure of welded joints of superconducting composite wire NT-50 of $1 \mathrm{~mm}$ diameter: $a$ - without etching $(\times 30) ; b-$ after microsection etching $(\times 150)$

of superconducting wire, reduces not more than per $10 \%$, that allows recommending the methods of percussion capacitor-discharge welding for joining of composite wires of superconducting $\mathrm{Ni}-\mathrm{Ti}$ alloy in copper matrix.

Therefore, percussion capacitor-discharge butt welding of superconducting composite wire of $\mathrm{Ni}-\mathrm{Ti}$ alloy in copper matrix allows producing the joints with the properties close to that of the base metal.

1. Chyorny, O.V., Reshetnyak, E.N., Stetsenko, A.N. et al. (2002) Structure and superconducting characteristics of $\mathrm{Nb}-\mathrm{Ti} / \mathrm{Ti}$ superlattice. Voprosy Atom. Nauki i Tekhniki, 1, 84-87.

2. Shibuya, J., Mizutame, M., Nakanishi, K. (1987) Joining process and its feature of superconducting materials. J. JWS, 56(2), 12-16.

Received 29.01.2014 